\title{
Trabalho e natureza: uma leitura semântico-cognitiva em textos dos séculos XIX, XX e XXI
}

\author{
Work and nature: a semantic- \\ cognitive reading in texts of the \\ $\mathrm{XIX}, \mathrm{XX}$ and $\mathrm{XXI}$ centuries
}

Eliane Santos Leite da Silva ${ }^{1}$ https://orcid.org/0000-0001-6758-1776

\begin{abstract}
Resumo: No presente texto, socializaremos recortes de um estudo sócio-histórico-cognitivo a respeito das formas conceptualizadoras do TRABALHO, tendo como corpus textos jornalísticos dos séculos XIX, XX e XXI. O lastro teórico escolhido foi a Semântica Cognitiva, a partir dos contributos de Lakoff e Johnson (1987, 1999, 2002 [1980]), Lakoff (1987, 1993, 2012), Johnson (2007), Gibbs (1995), Grady (2007) e Soares da Silva (2010, 2009). Os resultados apontaram para conceptualizações do tipo TRABALHO É CRIAÇÃO, TRABALHO É SEMENTE, TRABALHO É GERAÇÃO, TRABALHO É FRUTO, mapeadas no domínio da experiência que denominamos da natureza. Esperamos que, através deste estudo, seja possível ventilar como se deram os mapeamentos no âmbito do domínio da experiência selecionado.
\end{abstract}

Palavras-Chave: Semântica Cognitiva; Trabalho; Conceptualização.

Abstract: In the present text, we will socialize cuts of a socio-historical-cognitive study about the
conceptualizing forms of WORK, having as corpus journalistic texts of the XIX, XX and XXI
centuries. The theoretical framework chosen was Cognitive Semantics, based on contributions

${ }^{1}$ Instituto Federal Baiano. E-mail: elianesleite1@hotmail.com / elianesleite@yahoo.com.ar 
from Lakoff and Johnson (Lakoff and Johnson, 1987), Lakoff (1987, 1993, 2012), Johnson (2007), Gibbs (1995), Grady (2007) ) and Soares da Silva (2010, 2009). The results pointed to conceptualizations of the type WORK IS CREATION, WORK IS SEED, WORK IS GENERATION, WORK IS FRUIT, mapped in the realm of the experience we call nature. We hope that, through this study, it will be possible to ventilate as the mappings were given within the domain of the selected experiment.

Keywords: Cognitive Semantics; Job; Conceptualization.

\section{Introdução}

Até o século XIX, as pesquisas em Linguística objetivavam, em linhas gerais, realizar levantamentos de dados da língua com interesses histórico-comparativistas, em perspectiva diacrônica. O início do século XX reconfigura esse quadro, tratando a língua enquanto sistema dicotômico, através de metodologias que primavam por uma abordagem opositiva da língua. Como um dos interesses dos estudiosos era que a Linguística alcançasse o status de ciência, os mesmos precisavam adequar-se aos modelos das pesquisas em ciências exatas, o que exigiu o máximo de tentativas para alcançar a chamada "objetividade" no tratamento dos dados, o que se refletia em extensas quantificações e na exclusão do sujeito dos referidos estudos.

A partir de meados do século XX, tal modelo sofreu muitas críticas. A análise da intensa troca linguística entre os humanos, gerada pelos avanços tecnológicos, não mais poderia limitarse à quantificação e comparação dos dados de língua isoladamente, de modo que os procedimentos teórico-metodológicos de determinadas correntes de estudos linguísticos assumiram outra motivação: contextualizar os resultados das pesquisas, considerando tanto o sujeito falante quanto sua cultura.

Novos caminhos na ciência em geral proporcionaram mudanças epistemológicas, também nos estudos linguísticos que partiram, então, do pressuposto de que analisar a língua não deveria ser mais um processo restrito aos dados coletados em uma determinada situação linguística; antes, pressupunha o considerar a intrínseca relação entre o sujeito usuário da língua e seu contexto cultural específico. Como, portanto, não considerar tal imbricação no processo de funcionamento da língua? Reconhecendo ser impossível tal façanha, diferentes perspectivas de análise linguística têm contribuído para o amadurecimento de abordagens da língua mais holísticas e dialogantes. Como a herança filosófica ocidental é predominantemente disciplinar, é tarefa ousada optar por um caminho interdisciplinar para a abordagem da análise linguística. Os estudos semânticos mais contemporâneos têm apresentado essa preocupação. Porém, tal inquietação nem sempre permeou os estudos dessa área do saber linguístico, em específico, 
como aqueles voltados ao estudo da significação.

A princípio, a Semântica pode ser entendida como a área dos estudos linguísticos cujo interesse de investigação repousa sobre a significação. Não desconsideramos, todavia, o fato de que tal conceito seja diretamente dependente do enfoque dado nos estudos propostos, ultrapassando, muitas vezes, o âmbito linguístico, de acordo com cada abordagem, dentre as quais podemos indicar as semânticas: Lexical, Formal, Argumentativa, Computacional, Cultural, da Enunciação, dos Protótipos e a Cognitiva, sendo esta última a que mais interessa à presente investigação. O ponto em comum, nos estudos das referidas abordagens semânticas, é o interesse pelo significado nas linguagens humanas em suas mais diversas nuances; porém definilo, até então, não tem sido uma tarefa simples, já que a própria noção de significado é flutuante e relaciona-se a questões filosóficas e epistemológicas, além de implicações advindas do histórico de vida, das relações com o mundo, dos conhecimentos culturais de cada um, além do próprio contexto situacional que envolve determinada construção que pretenda ser compreendida.

Enquanto subárea da Linguística Cognitiva (doravante LC), a Semântica Cognitiva (doravante SC) busca compreender os diversos fenômenos da categorização e da conceptualização humanas, ou seja, como os conceitos e os significados são estruturados na mente, a partir de fenômenos como metáfora e a metonímia, em uma perspectiva experiencialista.

\section{A Semântica Cognitiva: breve contextualização nos estudos linguísticos}

Como na presente investigação, nos fundamentamos nos pressupostos teóricos e metodológicos da SC, optamos por considerar essa perspectiva, especialmente ao tratar dos processos de conceptualização. Nesse aspecto, os principais inauguradores da SC, George Lakoff e Mark Johnson (2002 [1980]), desconstroem a perspectiva objetivista então predominante na maioria dos estudos linguísticos ao apontarem o que seja o significado, partindo de um ponto de vista experiencialista, segundo o qual, o significado não existe per si, antes é construído pelo sujeito, a partir de suas interações no mundo, através do seu corpo. A este respeito, Lakoff (1987) defende que tal abordagem busca caracterizar o significado em termos da natureza e da experiência dos organismos durante o processamento do pensamento e, ainda, mais radicalmente, assevera que o significado "não é uma coisa, ele envolve o que é significativo para nós. Nada é significativo em si mesmo [...] deriva da experiência de funcionar 
como um ser de uma determinada espécie em um determinado ambiente. (LAKOFF, 1987, p.292. Grifo nosso) $)^{2}$.

Assim, para além de uma interação mente-corpo, o experiencialismo defendido na SC rejeita a dicotomia objetivista sujeito-objeto, que exclui a experiência do sujeito na construção do conhecimento, pressupondo que os objetos sejam independentes da interação do sujeito com o mundo, a fim de reinterpretá-lo e reconstruí-lo. (LAKOFF; JOHNSON, 1999). Partindo desses pressupostos, poder-se-ão entender as formas de conceptualização do mundo, por meio de fenômenos como as metáforas e metonímias conceptuais, além dos esquemas de imagens, já que os mesmos "são significativos porque estão baseados nos conceitos diretamente significativos e nas correlações de nossa experiência" (CASTILLO, 2008, p.196) ${ }^{3}$. Esse caráter holístico na abordagem dos fenômenos de conceptualização, enquanto relacionados às interações entre corpo, sujeito e ambiente, é uma das características distintivas da SC, em relação às formas de abordagem do significado defendidas por outras perspectivas de estudos semânticos aqui já citados.

O presente estudo assumiu esse viés cognitivista, uma vez que buscou compreender as formas de conceptualização do trabalho através de mecanismos conceptuais, como a metáfora, a metonímia e os esquemas imagéticos emergentes nos Modelos Cognitivos Idealizados (doravante $\mathrm{MCl}$ ) identificados. O material linguístico sobre o qual nos debruçamos, a fim de investigar tal fenômeno conceptual, correspondeu a textos jornalísticos impressos ${ }^{4}$, datados entre os séculos XIX e XXI.

As inquietações que nortearam a presente investigação visaram a apresentar as formas de conceptualização do trabalho identificadas nos referidos textos, buscando compreender de que forma as mesmas se evidenciaram na língua portuguesa, no âmbito da documentação pertencente ao lastro temporal selecionado, de modo a apontar para possíveis mudanças e/ou permanências no sistema conceptual do trabalho. Para tanto, partimos da hipótese de que o estudo de usos específicos da língua portuguesa, em uma perspectiva semântico-cognitivista, contribuiria com a compreensão sobre o caráter experiencialista das formas de

\footnotetext{
${ }^{2}$ Tradução nossa do original: "Meaning is not a thing; it involves what is meaningful to us. Nothing is meaningful in itself. [...] derives from the experience of functioning as a being of a certain sort in an environment of a certain sort".

3 Tradução nossa do original: "Las metáforas son significativas porque están basadas en los conceptos diretacmente significativos y en las correlaciones de nuestra experiencia".

${ }^{4}$ Informamos que são os textos impressos, visto que, no caso dos textos do século XXI, há versões apenas online de alguns jornais. O que não é o caso do jornal investigado.
} 
conceptualização identificadas no sistema conceptual dos escreventes, mediante pistas deixadas em suas escritas.

Assim, traçamos como objetivo de pesquisa realizar um levantamento das expressões linguísticas que instanciaram as formas de conceptualização de trabalho nos textos jornalísticos selecionados, a fim de esquadrinharmos como tais formas de conceptualização se evidenciaram na língua portuguesa como pistas para discutirmos o processo de conceptualização do trabalho. A pesquisa assumiu um caráter qualiquantitativo, descritivo-interpretativo e documental, a partir de uma perspectiva semântico-cognitivista. Os documentos que compuseram o corpus estão publicados no jornal brasileiro O Estado de São Paulo, cujos originais estão disponíveis online. O recorte selecionado para socialização no presente texto é composto por 24 ocorrências. Após o levantamento das ocorrências, debruçamo-nos sobre cada uma delas, a fim de identificarmos os domínios da experiência evocados e as formas de construções conceptualizadoras adotadas. Em seguida, fizemos um levantamento das particularidades das ocorrências, de modo a discutir o comportamento dos processos cognitivos observados.

Nesse sentido, buscamos identificar as formas de conceptualização, por meio de esquemas imagéticos, metáforas e metonímias conceptuais, enquanto caracterizadores de um determinado tipo de escrita, no que diz respeito às crenças, valores e costumes dos escreventes, partindo do pressuposto de que há, em toda e qualquer sociedade, uma intensa relação entre as manifestações linguísticas, culturais, experienciais e conceptuais.

No domínio da experiência da natureza, identificamos o modelo cognitivo idealizado da criação, que será discutido em seguida.

\section{O trabalho no domínio da experiência da natureza}

Ao considerarmos a situação contemporânea do mundo do trabalho no Brasil, notamos que a instabilidade no emprego tem acarretado a propagação do sentimento de não-pertença, mediante o fenômeno cunhado por Antunes (2011 [1995], p.38), como sendo o "desemprego estrutural", ocasionado pelo aumento de mão-de-obra que não pode ser absorvida pelo mercado, não mais por um período determinado, mas configurando um estado social que parece ser permanente.

Em especial, pelo incremento das novas tecnologias nos processos produtivos, antigos postos de trabalho que dependiam da manipulação humana passaram a ser substituídos por máquinas, além de muitos setores de prestação de serviços, por exemplo, que já são considerados desnecessários, visto que o mundo em rede, resultante do incremento das formas 
de novas tecnologias aplicadas aos meios de comunicação, encurtou distâncias, reduziu gastos e relativizou a dependência da ação humana direta para a consecução de determinadas atividades. Vive-se, nesse contexto, o que Castells (2000) entende como um dos intervalos que marcam a história humana, e "cuja característica é a transformação de nossa 'cultura material' pelos mecanismos de um novo paradigma tecnológico que se organiza em torno da tecnologia da informação" (CASTELLS, 2000, p.67).

Concordamos com Morin (2011, p.234), ao pontuar que:

O trabalho físico que utiliza a energia humana está diminuindo graças à automatização e à robotização dentro das fábricas. O trabalho industrial também está se reduzindo a favor do desenvolvimento dos serviços e o auge do trabalho informatizado 5 .

Assim, a sensação de constante não pertencimento em relação ao trabalho é seguida pelo rápido movimento de substituição e "descarte" dos trabalhadores. Bauman (2000) associa esse processo de não identificação com a transição da atividade artesanal para o estabelecimento da produção fabril, em que o interesse pelas atividades laborais, como sendo algo honroso e que deveria ser o alvo do trabalhador, foi sendo, aos poucos, desgastado pela nova configuração hierárquica nos ambientes das indústrias.

Assim, percebemos como esse entrelaçamento de propósitos afetos ao trabalho modificou, inclusive, as relações humanas, que, a partir de então, reafirmam os lugares sociais, através da hierarquização trabalhista. Na perspectiva baumaniana, tal migração dos processos produtivos acarretou na perda da emoção característica nos processos artesanais, em detrimento do distanciamento ocasionado pela racionalidade do mercado, já que o caráter mais particularizado do mesmo não faz mais sentido no âmbito da coletividade, o que conduziu à perda de sentido na realização do trabalho.

\section{O modelo cognitivo idealizado da criação: considerações interpretativas sobre o corpus}

Nas ocorrências que se enquadraram no modelo cognitivo $(\mathrm{MCl})$ da CRIAÇÃO,

${ }^{5}$ Tradução nossa do original: "El trabajo físico que utiliza la energía humana está disminuyendo gracias a la automatización y a la robotización dentro de las fábricas. El trabajo industrial también se está reduciendo a favor del desarrollo de los servicios y el auge del trabajo informatizado". 
podemos inferir essa transição de conceptualizações, iniciando pela valorização do processo produtivo em seu aspecto criativo, até à perspectiva mais atomizada do trabalho contemporâneo, em relação ao trabalhador. Observemos a seguir como as mesmas se deram.

Em (1), por exemplo, houve uma alusão ao caráter criativo/criador do trabalho:

(1) E que triste e desoladora perspectiva esta - de vastas officinas e ruidosas fabricas desertas, sem mais a movimentação fecunda do trabalho - e as profundas minas, abandonadas, abrindo para os céus as gargantas escuras - num tenebroso bocejo. (ANÔNIMO. Crônica. O Estado de São Paulo. Dia a dia, p.1, 01 maio 1892) ${ }^{6}$.

Percebemos a retomada metonímica do trabalho como o lugar de sua realização, mais especificamente, as "vastas officinas e ruidosas fabricas" e "as profundas minas", acionando a conceptualização metafórica trabalho é lugar. Assim, a partir do momento em que as fábricas estavam desertas, seria um indicativo de que o trabalho não estava sendo executado, ideia também reforçada pelo trecho "sem mais a movimentação fecunda do trabalho", que nos sugeriu as metáforas trabalho é gerador de movimento e trabalho é gerador de movimento fecundo. Nesse aspecto, entendemos que essa ocorrência pertence ao MCI da CRIAÇÃO, na medida em que, ao lançar mão de termos como fecundo e movimento, aciona saberes enciclopédicos a respeito dos processos de fecundação humana, que envolvem a movimentação das células reprodutivas masculinas até o encontro das células femininas, que, em sendo ambas férteis e ativas nesse processo, em um ambiente específico, gerarão uma nova vida. Assim, temos que trabalho é produção, resultante da conceptualização trabalho é gerador de movimento.

A ocorrência (2) apresenta elementos relacionados às discussões apontadas, como pudemos observar no texto "As commemorações do dia 1 de maio na capital do paiz":

(2) A hora histórica que estamos vivendo em meio às difficuldades criadas pelas inquietações do mundo contemporaneo, bem está a exigir um máximo de esforço e de dedicação da parte de todos quantos num immenso esforço anonymo das massas trabalhadoras cimentam a grandeza da nacionalidade. Que seja abemçoado pela Providencia esse trabalho fecundo do operariado brasileiro e que delle exsurja maior e mais pujante sempre a arvore bendita da riqueza da prosperidade que há de fazer do Brasil um dos mais bellos florões da civilisação humana. Cordialmente Waldemar Falcão (ministro do trabalho). (ANÔNIMO. As commemorações do dia 1 de maio na capital do paiz. O Estado de São Paulo. p.2,01 maio 1938).

\footnotetext{
${ }^{6}$ As escritas originais foram mantidas, em todos os aspectos.
} 
Explorando aspectos relacionados ao mundo vegetal, o escrevente se apropriou de expressões como: "trabalho fecundo do operariado brasileiro", "arvore bendita da riqueza da prosperidade", "mais bellos florões da civilisação humana". Ao qualificar o trabalho como fecundo, entendemos que o mesmo se ancorou na elaboração metafórica trabalho é semente, visto apontar para a possibilidade de produzir vida, metaforizada, ainda, pela expressão arvore. Assim, entendemos que, do mesmo modo que semente é geradora de árvore, trabalho é gerador de prosperidade, visto que prosperidade é árvore ("arvore bendita da riqueza da prosperidade").

A partir dos ciclos de vida dos vegetais, sabemos que, antes de uma árvore produzir frutos, há a geração de flores, que, no texto, é associada à "civilisação humana"; assim, temos a correspondência: flores precedem frutos, do mesmo modo que prosperidade precede civilização. Como a prosperidade resultante do fecundo trabalho, temos que a força motriz da civilização humana é o trabalho fecundo, de onde podemos inferir a metáfora complexa trabalho é gerador de civilização humana, ancorada no El do CICLO.

Um aspecto a ser posto é que tal geração não é atribuída a um agente específico; no trecho "trabalho fecundo do operariado brasileiro", ocorre, a nosso ver, um apagamento do sujeito, pois não se identifica quem seja a "massa" que trabalha. Assim, trabalho coletivo é atividade de geração anônima.

No texto "Desemprego pode cair para níveis de 96", o tema do avanço da economia brasileira é discutido a partir de diversas conceptualizações metafóricas, em que ocorre a predominância de elementos do $\mathrm{MCI}$ da CRIAÇÃO. Sendo um texto que trata da importância da movimentação econômica, em um período de transição de séculos (do XX para o XXI), a estratégia de convencimento de que o governo mantém o controle sobre o avanço econômico sobre a vida do país pareceu-nos ser uma das motivações para tal escrita. Assim, o ancorar-se na "geração de empregos", e, consequentemente, aumento de renda (melhoria da qualidade de vida) da população converteu-se em uma estratégia a ser utilizada, especialmente pelo fato de ser divulgada pela mídia nacional impressa, visando ao público eleitor, através de seus diversos canais de comunicação. Observemos mais detidamente como compreendemos tais elaborações, ao longo do texto, no qual identificamos as ocorrências que discutiremos em seguida.

O título em questão, "Desemprego pode cair para níveis de 96", aponta para um uso conceptual sobre o "desemprego", ancorado no El do RECIPIENTE. Considerando que o "nível", a que se refere, é uma forma de medir um fluido em um recipiente, em que a marcação externa mais elevada sugere crescimento, e a menos elevada, diminuição, constatamos que o 
"desemprego" pode ser entendido, a partir de uma metáfora ontológica, como uma substância ou fluido que se dilata ou se retrai; desta forma, entendemos ter sido acionado o El CHEIOVAZIO, que sugere, respectivamente, aumento/diminuição de quantidades.

Em (3) e (4), também observamos este acionamento do referido El, além do El do PROCESSO, já que o trecho aponta para um "Crescimento e emprego para todos", sendo associado, como na ocorrência seguinte, ao "movimento de aumento", destacando o aspecto dinâmico das relações econômicas:

(3) Crescimento e emprego para todos. É o que desejamos comemorar nos próximos dias do trabalho. (ANÔNIMO. Propaganda. O Estado de São Paulo. p.9, 01 maio 1991).

(4) "Foi um aumento de 3,8\% sobre março de 99", disse o secretário. "Isso mostra que continua o movimento de aumento da criação de emprego, na margem". (OTTA, Lu Aiko. Desemprego pode cair para níveis de 96. O Estado de São Paulo. p.37, 01 maio 2000).

A partir da leitura, do texto integral, em que identificamos a ocorrência (4), por exemplo, observamos os seguintes mapeamentos: o recipiente é cenário brasileiro, o fluido é o desemprego e o nivelador é a medição do desemprego no ano de 1996. Assim sendo, temos, a partir do título, a metáfora desemprego é um fluido em um recipiente, já que pode ser dilatado ou diminuído, e, portanto, medido.

Em uma elaboração que trata algo aparentemente negativo, como sendo positivo, a expressão "Desemprego pode cair para níveis de 96" o escrevente nos pareceu destacar o aspecto positivo dessa informação: em que uma diminuição no nível corresponde a um aspecto positivo na experiência econômica brasileira naquele momento. Assim, as metáforas orientacionais para cima é positivo, para baixo é negativo (LAKOFF; JOHNSON, 2002 [1980]), foram ressignificadas, em ocorrências que apontam contrário: para baixo é positivo, na metáfora queda do desemprego é algo positivo.

Essa ressignificação apareceu, também, na ocorrência (5), em que o aumento da taxa de desemprego é conceptualizado como algo negativo, sendo que a "expectativa" do governo é, portanto, sua diminuição:

(5) A expectativa de Amadeo é que a taxa de desemprego recue dos atuais $8,1 \%$, registrado em março, para algo como 5,5\% - o mesmo nível de antes das crises asiática, russa e brasileira - no fim de 2001. (OTTA, Lu Aiko. Desemprego pode cair para níveis de 96. O Estado de São Paulo. p.37, 01 maio 2000). 
Tal desconstrução do próprio aspecto primário dessa metáfora (GRADY, 2007), corrobora a ideia de Kövecses (2010), segundo o qual, somente em contexto é que algumas formas de conceptualização farão sentido. Assim, temos que trabalho é algo que pode ser medido, pelo El da VERTICALIDADE, que, nesse aspecto, estruturou a conceptualização de forma inversa, perspectivando uma elaboração metafórica em que aumento da taxa de desemprego é algo negativo e seu oposto seria aumento da taxa de emprego é algo positivo, o que, por acarretamento nos sugere que maior taxa de emprego é algo positivo, visto que emprego é algo positivo.

Em (6), observamos a estratégia do escrevente ao desenvolver a ideia proposta no título, através do comparativo com medições do nível da economia nacional realizadas anteriormente, no ano de 1996:

(6) A criação de empregos na economia brasileira está em níveis que não se viam desde outubro de 96, segundo informou ao Estado o secretário de política econômica, Edward Amadeu. (OTTA, Lu Aiko. Desemprego pode cair para níveis de 96. O Estado de São Paulo. p.37, 01 maio 2000).

$\mathrm{O} \mathrm{MCl}$ da criação foi acionado nas expressões como "criação de empregos na economia brasileira" (6), que nos remeteram à metáfora ontológica emprego é fruto, recorrente no âmbito da economia (pela preposição em), de modo que, metonimicamente, temos economia por lugar.

(7) Em março, segundo dados divulgados na quinta-feira, pelo IBGE, foram
criados 620.616 novos postos de trabalho, na comparação com março do
ano passado. (OTTA, Lu Aiko. Desemprego pode cair para níveis de 96.0 Estado de São Paulo. p.37, 01 maio 2000).

(8) A abertura de novos postos de trabalho está relacionada com o aquecimento na economia que vem sendo registrado desde o fim do ano passado. (OTTA, Lu Aiko. Desemprego pode cair para níveis de 96. O Estado de São Paulo. p.37, 01 maio 2000).

Nos trechos "foram criados 620.616 novos postos de trabalho [...]" e "a abertura de novos postos de trabalho" (7), inferimos uma conceptualização metaftonímica, em que a metáfora trabalho é posto, foi motivada pela metonímia espaço de trabalho por trabalho. Assim, temos o acarretamento criar postos é criar oportunidades de trabalho. Ao proporcionar uma associação entre o local de trabalho e as atividades que nele serão desenvolvidas, em (8), notamos a evocação da metonímia trabalho por posto e, considerando que "assumir" um posto, 
acarreta em tomar para si responsabilidades, percebemos a metáfora trabalho é responsabilidade, visto que, se alguém "assume" a empresa, será somente uma consequência responsabilizar-se pelo que advirá dessa ocupação.

Em (10), o trecho "há crescimento na abertura de novas vagas" aparece, como consequência do "crescimento do Produto Interno Bruto (PIB)" (9), em que podemos aventar uma ancoragem nos EI's do PROCESSO e do EQUILÍBRIO, em que o PIB e as vagas de emprego estão em uma relação de dependência, de sorte que, se há crescimento do PIB, haverá possibilidades de trabalho, na medida em que se "aumentem as vagas":

\begin{abstract}
(9) Neste ano, o governo espera um crescimento do Produto Interno Bruto (PIB) de $4 \%$, ante cerca de $0,5 \%$ registrado em 99 . Por isso, é de se esperar que aumentem as vagas. (OTTA, Lu Aiko. Desemprego pode cair para níveis de 96. O Estado de São Paulo. p.37, 01 maio 2000).

(10) O secretário refere-se ao fato de que há crescimento na abertura de novas vagas, nos dados mensais mais recentes, embora esse efeito não apareça quando se consideram as taxas de desemprego de um período maior de meses. (OTTA, Lu Aiko. Desemprego pode cair para níveis de 96. O Estado de São Paulo. p.37, 01 maio 2000).
\end{abstract}

Novamente, a economia - aqui metonimizada pelo PIB - é um fluido que, elevando seu nível, por dilatar-se, em um recipiente (que seria o contexto social do país), eleva, igualmente, o número de vagas de trabalho. Porém, como a oferta foi menor do que a procura, o texto desconstrói esta expectativa, quando, em (11) e (12), aponta que não há trabalho suficiente para todos:

\footnotetext{
(11) Ao mesmo tempo em que surgiram novas vagas, também aumentou o número de pessoas procurando emprego - principalmente mulheres e jovens, que saíram à busca de trabalho, após a crise internacional, na tentativa de recompor a renda familiar. (OTTA, Lu Aiko. Desemprego pode cair para níveis de 96. O Estado de São Paulo. p.37, 01 maio 2000).
}

Com o aumento da oferta de novas oportunidades de trabalho, houve maior procura pelas mesmas. O escrevente, assim resume tal busca: "principalmente mulheres e jovens, que saíram à busca de trabalho, após a crise internacional, na tentativa de recompor a renda familiar" (11), que "não encontrou vagas por causa do impacto da crise financeira internacional do Brasil" (12). Diante dos fatos apresentados, pudemos inferir a conceptualização trabalho é um bem que se procura, ancorada na metáfora geral trabalho é bem precioso (LAKOFF; JOHNSON, 2002[1980]): "pessoas procurando emprego", "saíram à busca de trabalho" (11) e "não 
encontrou vagas" (12):

\begin{abstract}
(12) Há um estoque de pessoas que tentou entrar no mercado de trabalho a partir de outubro de 97 e não encontrou vagas por causa do impacto da crise financeira internacional do Brasil. Agora, com a economia em processo de reaquecimento, esse estoque está sendo gradualmente absorvido. Por isso, a taxa de desemprego começará a recuar a partir do segundo semestre deste ano. (OTTA, Lu Aiko. Desemprego pode cair para níveis de 96. O Estado de São Paulo. p.37, 01 maio 2000).
\end{abstract}

O trecho "Há um estoque de pessoas que tentou entrar no mercado de trabalho" (12) aponta para o El do RECIPIENTE, em que mercado de trabalho é lugar, onde as pessoas "tentaram entrar", indicando, além disso, o El do BLOQUEIO, indicando que, para conseguir tal "entrada" seria necessário um emprego de forças significativo.

O trecho "com a economia em processo de reaquecimento, esse estoque está sendo gradualmente absorvido. Por isso, a taxa de desemprego começará a recuar" (12) aponta para o acionamento do El do PROCESSO, visto que uma espécie de ciclo se deslinda diante de nós: a economia, como um fluido em um recipiente, ao se aquecer (novamente) eleva o seu nível; isso ocasiona a absorção do "estoque" (pessoas procurando trabalho), o que, em consequência, faz a taxa de desemprego recuar, pelo aumento do número de novos empregados. Em um cluster model, notamos a mescla de vários El's (como os do PROCESSO, RECIPIENTE, CONTRAFORÇAS, EQUILÍBRIO, CICLO) operando na estruturação da metáfora conceptual movimento da economia gera trabalho. Ao deduzirmos esta metáfora complexa, notamos que outros acarretamentos se agruparam, como: economia é um fluido em um recipiente, pessoas sem trabalho formam um estoque, pessoas sem trabalho são uma substância a ser absorvida, absorver estoque é gerar trabalho, aumento da economia gera diminuição de desemprego, e, em consequência, seu oposto: aumento da economia gera aumento de emprego.

Em (13) e (14), o escrevente apresenta a especificidade do tipo de trabalho que tem surgido, no âmbito da nova situação econômica, através da distinção entre o emprego formal e o informal:

(13) Um dado que chamou a atenção do governo é que as novas vagas que estão surgindo são, em sua maior parte, as chamadas informais, ou seja, sem carteira assinada. (OTTA, Lu Aiko. Desemprego pode cair para níveis de 96. O Estado de São Paulo. p.37, 01 maio 2000).

(14) Segundo dados do IBGE, das 620.616 novas vagas abertas em março apenas 92.424 foram com carteira assinada, contra 454.346 sem carteira fora os 67.152 trabalhadores por conta própria e 3.838 novos 
empregadores surgidos no período. (OTTA, Lu Aiko. Desemprego pode cair para níveis de 96. O Estado de São Paulo. p.37, 01 maio 2000).

O primeiro, emprego formal, o é por conta do registro em carteira, o que implica em mais segurança para o trabalhador, no sentido de que uma possível demissão gerará mais gastos para o empregador, enquanto que a modalidade informal, "ou seja, sem carteira assinada" (13), é mais instável para o trabalhador. Assim, também, pelas ocorrências seguintes, compreendemos que trabalho formal é legal, enquanto que trabalho informal é ilegal:

(15) "Há uma tese, com a qual não concordo, que o crescimento econômico por si só diminui a informalidade", disse o secretário. "Eu diria que o crescimento não atrapalha, mas também não explica tudo, pois entre 94 e 97, o País cresceu muito e a proporção de trabalho ilegal não caiu". (OTTA, Lu Aiko. Desemprego pode cair para níveis de 96. O Estado de São Paulo. p.37, 01 maio 2000).

(16) O avanço do emprego ilegal mostra que o atual formato do emprego formal precisa ser revisto. (OTTA, Lu Aiko. Desemprego pode cair para níveis de 96. O Estado de São Paulo. p.37, 01 maio 2000).

(17) No primeiro trimestre de 2016, como já previsto pelos analistas, [o desemprego] atingiu o assustador índice de 10,9\%, ou 11,1 milhões de trabalhadores no olho da rua. Somente o setor industrial, em 12 meses contando até março, fechou 1,52 milhão de postos de trabalho. (PANOSSIAM, Paulo. Fórum dos leitores - O grande golpe: descalabro econômico. O Estado de São Paulo. p.2, 01 maio 2016).

As expressões "a proporção de trabalho ilegal não caiu" (15) e "o avanço do emprego ilegal" (16) apontam, ao mesmo tempo, para uma distinção e uma aproximação semântica entre trabalho e emprego; assim, entendemos que o fator diferenciador entre ambos é o aspecto da formalização via carteira de trabalho. Dessa forma, temos a metonímia tipo da atividade pela atividade, mais especificamente, trabalho formal por emprego. Como o crescimento de um ocasiona o do outro ("o crescimento econômico por si só diminui a informalidade" (15)), percebemos sua estruturação por meio do El do EQUILÍBRIO. A partir do trecho "o País cresceu muito e a proporção de trabalho ilegal não caiu" (15), captamos o uso metonímico do tipo todo pela parte, em que país é perspectivado em lugar de economia do país. O trecho "[o desemprego] atingiu o assustador índice de 10,9\%" (17) aponta para o El da SUBSTÂNCIA, visto que, assim como um fluido em um recipiente, ao aumentar sua dilatação, ocupa maior espaço em seu interior, assim também se deu com o aumento do desemprego, medido por meio dos "índices" então divulgados.

A fim de tentar explicar tal aumento da economia atrelado ao aumento de trabalho 
informal, o escrevente, em (18), lança mão de outra expressão metafórica, que nos remeteu ao MCI da CRIAÇÃO: "raiz da maior oferta de vagas":

(18) Na raiz da maior oferta de vagas sem carteira assinada, o secretário vê uma mistura de fatores que passam pela universalização dos serviços públicos de saúde, pelo processo inflacionário das últimas décadas e até pela relação do cidadão com o governo. Ele avalia que a Constituição de 88, ao estender a todos os cidadãos o acesso ao serviço público de saúde, acabou desvalorizando a carteira de trabalho - até então exigida para dar acesso ao atendimento. (OTTA, Lu Aiko. Desemprego pode cair para níveis de 96. O Estado de São Paulo. p.37, 01 maio 2000).

Como nossa experiência com raízes, na natureza, se dá, prototipicamente, com aquelas do tipo subterrâneo (ainda que haja as de tipo aéreas ou externas, por exemplo), associamos a raiz a algo que é o sustentáculo do vegetal, e que, portanto, encontra-se em sua base, como um fundamento, um alicerce. Dessa forma, temos, em (18), "Na raiz da maior oferta de vagas sem carteira assinada, o secretário vê uma mistura de fatores", raiz por fundamento (metonímia), ao mesmo tempo em que raiz é causa do crescimento (metáfora).

No trecho, "acabou desvalorizando a carteira de trabalho" (18), observamos a metonímia do tipo documento pela atividade, em que carteira de trabalho está em lugar de trabalho formal.

Em conclusão ao texto "Desemprego pode cair para níveis de 96", em (19), a expressão criam também retoma o $\mathrm{MCI}$ da CRIAÇÃO:

(19) As diferenças entre o emprego com carteira assinada e sem carteira assinada criam dois tipos totalmente diferentes de trabalhador no Brasil, avalia o secretário. (OTTA, Lu Aiko. Desemprego pode cair para níveis de 96. O Estado de São Paulo. p.37, 01 maio 2000).

O agente criador, nesse caso, refere-se aos tipos de trabalho: "o emprego com carteira assinada e sem carteira assinada", e os frutos seriam "dois tipos totalmente diferentes de trabalhador no Brasil". Desse modo, temos a metáfora genérica trabalho é criador, mais sistematizada em tipo de trabalho é gerador de tipo de trabalhador; e, por acarretamento, tipo de trabalhador é fruto.

Em continuação à estruturação do $\mathrm{MCl}$ da CRIAÇÃO, o escrevente do texto "Temer quer fechar 2016 criando empregos", em que foram localizadas as ocorrências (20), (21), (22), (23) e (24), discutidas em seguida, apropria-se de alguns elementos da incerteza e do não- 
pertencimento do trabalhador ao seu lugar/posição laboral, e, a nosso ver, elabora toda uma argumentação propagandística sobre as propostas de melhoria do cenário econômico, por um novo governo do Brasil. A referida reportagem versa, especificamente, sobre as estratégias que seriam adotadas pelo, então, vice-presidente da República, Michel Temer, no caso de vir a assumir o poder, em função do impeachment da então presidenta Dilma Rousseff. De acordo com o texto, tal estratégia de desenvolvimento da economia, a ser praticada por sua equipe financeira serviria como medida emergencial, também, para amenizar a insatisfação popular e minimizar a grave crise econômica enfrentada pelo país, no ano de 2016, especialmente no setor trabalhista. Passemos a observar como se deram as referidas estratégias, a partir das seguintes ocorrências:

(20) Eventual governo acredita em retomada com a criação de 100 mil vagas formais. (ALVES, Murilo Rodrigues. Temer quer fechar 2016 criando empregos. O Estado de São Paulo. p.34, 01 maio 2016).

(21) O vice-presidente, Michel Temer, elegeu como prioridade de um eventual governo peemedebista recuperar a última bandeira conquistada pelo PT e perdida no ano passado: a geração de vagas com carteira assinada. (ALVES, Murilo Rodrigues. Temer quer fechar 2016 criando empregos. O Estado de São Paulo. p.34, 01 maio 2016).

(22) O esforço para chegar a 100 mil novas vagas será grande, tendo em vista que em 2015 foram fechados 1,54 milhão de postos com carteira assinada. Na hipótese de conseguir alcançar a marca, mesmo assim o resultado de 2016 será inferior ao de 2014 (quando foram geradas 420 mil vagas) e 2013 (1,138 milhão). Mas superior ao de 2012, quando foram criadas apenas 70 mil vagas. (ALVES, Murilo Rodrigues. Temer quer fechar 2016 criando empregos. O Estado de São Paulo. p.34, 01 maio 2016).

(23) A queda no desemprego virou uma das grandes vitrines de propaganda do governo petista. (ALVES, Murilo Rodrigues. Temer quer fechar 2016 criando empregos. O Estado de São Paulo. p.34, 01 maio 2016).

(24) Segundo os conselheiros de Temer, é possível criar 100 mil vagas neste ano, graças a alguns fatores, como a volta da credibilidade de uma nova equipe econômica, chefiada pelo ex-presidente do Banco Central, Henrique Meirelles. A mudança na percepção dos investidores destravaria as concessões de rodovias, aeroportos, rodovias e portos, e impulsionaria a criação de vagas no setor. (ALVES, Murilo Rodrigues. Temer quer fechar 2016 criando empregos. O Estado de São Paulo. p.34, 01 maio 2016).

Pela estrutura geral da reportagem "Temer quer fechar 2016 criando empregos", identificamos a recorrência de expressões metafóricas relacionadas ao $\mathrm{MCl}$ da CRIAÇÃO, no que tange ao nascimento e à atividade criadora, através do uso de expressões, como as destacadas, em: "retomada com a criação de 100 mil vagas" (20), "a geração de vagas com carteira assinada" (21), "foram criadas apenas 70 mil vagas" (22), "é possível criar 100 mil vagas 
neste ano", "impulsionaria a criação de vagas no setor" (24). O uso dos verbos criar e gerar acarretou, a nosso ver, na metáfora geral trabalho é criação, como estando subjacente ao texto.

Pudemos identificar uma das consequências dessa criação de vagas em (23): "A queda no desemprego virou uma das grandes vitrines do governo petista"; a relação, estruturada pelo El do BALANÇO, segundo a qual o aumento de vagas proporciona a diminuição do desemprego; resultados usados como "vitrine" ou como propaganda de governo, de modo a inferirmos que trabalho é propaganda, pela metáfora primária mais é positivo.

Nossa percepção sobre a estruturação do $\mathrm{MCl}$ da CRIAÇÃO contou, ainda, com o acionamento de conhecimentos enciclopédicos a respeito da criação/geração humana, a qual envolve alguns elementos como: os progenitores, os fatores de risco/favorecimento da fecundação, o ambiente de fecundação, as etapas de maturação, o parto de tipo "normal"7 e o crescimento de um novo ser. Tais mapeamentos puderam ser captados por nós em algumas expressões, como em "Eventual governo acredita em retomada com a criação de 100 mil vagas formais" (20), em que o eventual governo é o progenitor; "Segundo os conselheiros de Temer, é possível criar 100 mil vagas neste ano, graças a alguns fatores, como a volta da credibilidade de uma nova equipe econômica, chefiada pelo ex-presidente do Banco Central, Henrique Meirelles" (24), que seriam os fatores que favorecem a fecundação; "é possível criar 100 mil vagas neste ano" (24), como sendo o ambiente da fecundação, entendendo metonimicamente o tempo pelo lugar ("neste ano"), através da metonímia tempo por espaço, que no caso, em específico, temos o acarretamento: ano do governo pelo local da fecundação; "A mudança na percepção dos investidores destravaria as concessões de rodovias, aeroportos, rodovias e portos, e impulsionaria a criação de vagas no setor", "O esforço para chegar a 100 mil novas vagas será grande" (24), que associamos aos momentos das contrações, já que estas iniciam o processo de expulsão da criança, impulsionando-a para fora do útero, através do "esforço" da mulher, assim como acordos econômicos "impulsionariam" a criação de novas vagas. Percebemos, em (24), os EI's de RECIPIENTE e da ELIMINAÇÃO DE BARREIRAS, no sentido de que as vagas precisam de um "impulso" para serem "geradas", ou saírem à vista, de dentro de um lugar, que seria o projeto governamental.

Essas ocorrências sugeriram uma especificidade do processo de criação que não necessita, em todas as etapas, da contrapartida advinda de uma parceria de dois progenitores, visto que só o governo mobilizará suas estratégias para alcançar este objetivo. Essa

\footnotetext{
${ }^{7}$ Referimo-nos ao parto normal devido ao fato de que os mapeamentos identificados nas ocorrências nos pareceram mais associados, conceitualmente, com este tipo de parto.
} 
conceptualização aciona o modelo cultural contemporâneo das gestações independentes, a partir do qual as formas não convencionais de fecundação são, cada vez mais, utilizadas por mulheres com limitações de ordens diversas para conceberem, apontando para os múltiplos MCl's de mãe, amplamente discutidos por Lakoff (1987). Assim, a não dependência direta de um progenitor necessariamente conhecido pela mulher, para uma gestação física, projetou-se no domínio da empresa, como em (24): "Na hipótese de conseguir alcançar a marca, mesmo assim o resultado de 2016 será inferior ao de 2014 (quando foram geradas 420 mil vagas) e 2013 (1,138 milhão)", ao sugerir uma criação independente, de modo que, a partir do domíniofonte criação, entendemos ser o governo o gerador, e os resultados (ou domínio-alvo) como sendo os empregos.

Nesse contexto, o governo, metonimicamente representado pela expressão "Temer", atuaria como um agente criador e o trabalho, por sua vez, seria o resultado desta ação criativa, conforme sugere-nos o título da reportagem: "Temer quer fechar 2016 criando empregos". A partir disso, aventamos a conceptualização inicial temer é criador, que, por sua vez, aponta para seu acarretamento metafonímico governo é criador, como podemos observar no trecho "Eventual governo[...]", em (20), que especifica o agente não mais como uma única pessoa, mas ampliando seu sentido, como também percebemos em (21), pelo uso da expressão "prioridade de um eventual governo peemedebista". Assim, temos como acarretamento a metáfora conceptual trabalho é criação.

Percebemos, a partir das seguintes expressões: "a criação de 100 mil vagas formais" (20), "a geração de vagas com carteira assinada" (21), "postos com carteira assinada" (22), a especificação do tipo de trabalho ao qual se refere, a saber, atividade remunerada que seja formalizada mediante assinatura da carteira de trabalho, provavelmente como uma resposta às expectativas populares que reagiram às tentativas contemporâneas de precarização do trabalho, exigindo do governo medidas concretas de valorização do trabalhador, por meio do estabelecimento de relações mais seguras entre empresa-empregados.

Assim, o trabalho a ser criado é aquele de tipo formal, de onde podemos inferir a metonímia tipo de trabalho por trabalho. Ainda a respeito dos mesmos trechos, observamos que o uso das expressões "vaga" e "posto" (de trabalho) apontam para outra relação metonímica, ao tomar o local pela atividade (LAKOFF; JOHNSON, 2002 [1980]), ao indicar o espaço onde se realizará a atividade laboral.

No trecho "Na hipótese de conseguir alcançar a marca, mesmo assim o resultado de 2016 será inferior ao de 2014 (quando foram geradas 420 mil vagas) e 2013 (1,138 milhão). Mas superior ao de 2012, quando foram criadas apenas 70 mil vagas", em (22), notamos que, 
na expressão "geradas 420 mil vagas", houve uma remissão somente ao processo, sem especificar, nesse caso, os partícipes do ato de gerar, focando apenas no resultado do processo gerador. Assim, identificamos a conceptualização metafórica trabalho é geração, sendo esta uma metáfora mais geral, que englobou diversos outros acarretamentos. Julgamos possível inserir essa ocorrência no $\mathrm{MCl}$ da CRIAÇÃO, por compreendermos que esta corresponderia ao início do processo criativo, estando a ele subordinado. Após a geração, seguem-se diversos aspectos que envolvem o criar: assumir, cuidar etc.

Percebemos, ainda, que, na ocorrência, o escrevente lançou mão das metáforas primárias mais é positivo, menos é negativo (LAKOFF; JOHNSON 2002[1980]; KÖVECSES, 2010; GRADY, 2007), estabelecendo um comparativo entre o nível de crescimento da economia de anos anteriores com o de então; assim, se para 2014 e 2013 houve uma geração de vagas superior às 100.000 vagas propostas para 2016, esta marca supera o que fora alcançado somente em 2012 (70 mil).

\section{CONSIDERAÇÕES FINAIS}

Presente nos séculos XIX, XX e XXI, notamos que o MCI da CRIAÇÃO contou com formas de conceptualização de cunho metafórico e metonímico, estruturadas pelos El's, em suas formas de conceptualização do trabalho. Projetando conhecimentos do mundo natural - leia-se experiências humanas resultantes da interação corpo e natureza - notamos como os escreventes estabeleceram links conceptuais entre o trabalho e a natureza criativa, que se aplicaram à situação do mundo laboral, em suas problemáticas e desdobramentos atinentes ao seu próprio tempo e espaço.

\section{REFERÊNCIAS}

ANTUNES, Ricardo. Adeus ao trabalho? Ensaio sobre as metamorfoses e a centralidade do mundo do trabalho. 15. ed. - São Paulo: Cortez, 2011 [1. ed. 1995].

BAUMAN, Zygmunt. Trabajo, consumismo y nuevos pobres. Trad. Victoria de los Angeles Boschiroli. Barcelona: Editorial Gedisa, 2000

CASTELLS, Manuel. A sociedade em rede. Trad. Roneide Venancio Majer. Vol 1. 8.ed. São Paulo: Paz e Terra, 2000.

CASTILLO, Jesús Martínez del. La lingüística cognitiva: análisis y revisión. Madrid: Editorial Biblioteca Nueva, 2008 
GIBBS, Raymond W.; COLSTON, Herbert L. A realidade psicológico-cognitiva dos esquemas de imagem e suas transformações. In: SIQUEIRA, Maity; OLIVEIRA, Ana Flávia Souto de (Orgs.). Cadernos de Tradução - Linguística Cognitiva. Tradução: Larissa Brangel; Dalby Dienstbach. Porto Alegre, n. 31, jul-dez, 2012, p. 7-46. [obs- traduzido com a autorização dos autores, a partir do texto em inglês: GIBBS, R. W; COLSTON, H. L. The cognitive psychological reality of image schemas and their transformations. In: Cognitive Linguistics, Vol 6 (4), 1995, p.347-378].

GRADY, Joseph. Metaphor. In: GEERAERTS, Dirk; CUYCKENS, Hubert. (Eds.) The Oxford Handbook of Cognitive Linguistics. New York: Oxford University Press, 2007. p.188- 208.

JOHNSON, Mark. The meaning of the body: aesthetics of human understanding. Chicago \& London: The University of Chicago Press, 2007. Preface and Introduction - p.6-20.

KÖVECSES, Zoltán. Metaphor: a practical introduction. 2.ed. New York: Oxford University Press, 2010.

LAKOFF, George. No pienses en un elefante. Tradução: Magdalena Moura. Madrid: Editorial Compluetense, 2007.

LAKOFF, George. The contemporary theory of metaphor. In: ORTONY, Andrew. (Ed.) Metaphor and thought. 2.ed. New York: Cambridge University Press, 1993. p. 202-251.

LAKOFF, George. Women, fire, and dangerous things. Chicago: The University of Chicago Press, 1987.

LAKOFF, George; JOHNSON, Mark. Metaphors we live by. Chicago: University of Chicago Press, 1980. Tradução brasileira: Metáforas da vida cotidiana. ZANOTTO, Mara Sophia (coord. de tradução- Grupo GEIM). São Paulo: EDUC/ Mercado de Letras, 2002.

LAKOFF, George; JOHNSON, Mark. Philosophy in the flesh. Chicago: The University Chicago Press, 1999.

LAKOFF, George; JOHNSON, Mark. Philosophy in the flesh. Chicago: The University Chicago Press, 1999.

MORIN, Edgar. La vía para el futuro de la humanidad. Trad. Núria Petit Fontseré. Barcelona: Paidós, 2011.

SILVA, Augusto Soares da. Palavras, significados e conceitos: o significado lexical na mente, na cultura e na sociedade. In: Cadernos de Letras da UFF - Dossiê: Letras e cognição n. 41, p. 27-53, 2010. Disponível em: $<$ http://www.uff.br/cadernosdeletrasuff/41/artigo1.pdf >. Acesso em: 28 out. 2016.

SILVA, Augusto Soares da. A Sociolinguística Cognitiva: razões e escopo de uma nova área de investigação linguística. In: Revista Portuguesa de Humanidades - Estudos Linguísticos 13-1, 2009, pp.191212.Disponível

em: <https://www.academia.edu/19947180/A Sociolingu\%C3\%ADstica Cognitiva raz $\%$ C3\%B5es e esc opo_de_uma_nova_\%C3\%A1rea_de_investiga\%C3\%A7\%C3\%A30_lingu\%C3\%ADstica>. Acesso em: 28 out. 2016. 